\title{
Research on Flipped Classroom Teaching Mode From the Perspective of Multimodality*
}

\author{
Yingjie Liu \\ School of Foreign Languages, University of Jinan, Jinan, China
}

\begin{abstract}
Flipped classroom is not only the flipping of knowledge imparting and knowledge internalization, but also the all-round reform of education concept, teaching content, teaching methods, teaching means and teaching evaluation. Multimodality provides a theoretical perspective and analytical framework for the teaching design of flipped classroom. Multimodality theory fits many characteristics of flipped classroom, which is conducive to giving full play to the advantages of flipped classroom. With the help of multimodal theory and multimodal teaching ideas, this study constructs a flipped classroom teaching mode under the multimodal perspective, which takes the dynamic teaching structure as the core and the open multimodal learning environment as the all-round support, and gives some operational suggestions.
\end{abstract}

Index Terms - flipped classroom, multimode, multimodal teaching, teaching model

\section{INTRODUCTION}

The teaching process includes knowledge imparting and knowledge internalization. Although the two processes can not be strictly divided, generally speaking, the process of knowledge imparting and knowledge perception come first, and the process of knowledge internalization and knowledge understanding come second. Therefore, for the convenience of expression, we can divide the teaching process into two stages: knowledge imparting and knowledge internalization. In the traditional classroom, knowledge is mainly taught by teachers in the classroom, while knowledge internalization is mainly realized by students' homework or practice. Flipped classroom flips the process of knowledge imparting and knowledge internalization in traditional classroom, puts knowledge imparting after class, completed by students independently, puts knowledge internalization in class, discussed and completed through students' cooperation. Flipped classroom liberates the students and practices the "student-centered" education concept. Teachers change from the imparter of knowledge to the instructor and promoter of students' learning. It is a new teaching method which leads the new direction of classroom teaching reform.

Robert Talbert (2015) of Franklin College is one of the earliest scholars who paid attention to and practiced flipped classroom teaching. He put forward the teaching structure model of "before class + in class". On the basis of Robert model, Zhang Jinlei (2012) of Nanjing University refined the learning links and processes before and during class, which enhanced the operability of the structural model. In addition, Jackie Gerstin (2015), an American scholar, constructs a four-stage model of flipped classroom based on students' learning activities. From the perspective of teaching design, Zhong Xiaoliu (2013) of Tsinghua University put forward the Taiji ring model of flipped classroom. The above teaching models have played a positive role in promoting the current implementation of flipped classroom, leading the deepening and development of flipped classroom to a certain extent.

Although we pay attention to both students' learning and teachers' teaching, expand our vision from "before class + in class" to "after class + in class", focus on learning links and specific processes, and take "operability" and "practicability" as the criteria, we fail to break through the barriers of traditional teaching mode, It failed to further highlight the role and value of technology, so that we did not get the desired effect of change in the reality of flipped classroom teaching.

In the research, the author finds that multimodal theory is compatible with many characteristics of flipped classroom. What's more, multimodal theory helps to highlight the application of information technology in classroom teaching. Along this exploration path, the author tries to construct the flipped classroom teaching mode from the perspective of multimodality in order to reveal the true meaning of flipped classroom and achieve the desired effect of flipped classroom.

\section{Multimodality and Multimodal Teaching}

\section{A. Multimodality}

The term multimodality can be literally divided into two parts: multi and modality, which means the complexity of multiple modes. Many Modal thoughts can be traced back to the classical rhetoric of the fourth century BC, and it

\footnotetext{
* This paper serves for the Teaching and Research Program of School of Foreign Languages, University of Jinan (Number: WYJZ202004; Title: Research on Flipped Classroom Teaching Mode From the Perspective of Multimodality).
} 
comes from how to make voice, gesture and expression more conducive to the actual speech. However, it was not until the 1990s that multimodal theory was formed and developed with the development of information technology and the emergence of more expressions.

The concept of modality is very complex. Charles Forceville (2009), University of Amsterdam, defines the modality as a social symbol system explained by the specific perceptual process, such as image, text, gesture, sound, taste, contact, etc. Some other scholars regard the modality as the interaction between human senses and external environment, that is, the interaction modality, such as visual modality, auditory modality, taste modality, etc (G. Kress, 2009). In the field of human-computer interaction and artificial intelligence, some people regard the modality as the communication mode or information channel for human to perceive information. Multimodal human computer interaction is a system that responds to input in multiple modes or communication channels, such as voice, posture, writing and other modality. Corresponding to human sensory system, the input equipment of human-computer interaction includes camera, tactile sensor, microphone, olfactory equipment and taste equipment, and also includes some mixed input equipment, such as keyboard, mouse, writing board, motion input and biosensor. They correspond to two or more senses of human body.

At present, in the multimodal emotional interaction research, it's the focus to study large-scale body movement, posture, gaze and so on based on the visual research. Specifically speaking, face recognition, facial expression, posture recognition, human motion analysis and eye tracking are hot research topics. The modality can be realized by one or several media. Only one modality system is called single modality, and the system with two or more modalities is multimodality. With the rapid development of information technology, with the help of multimedia and high-tech, more modalities emerge. Multimodality has become normal in human life and communication.

There are many similarities between multimodality and multimedia. People often regard the paper, tape, CD-ROM and so on as the physical media, while the encoding method of loading content or information on physical media is called logical media, such as text, audio stream, video stream, etc. We can use logical media to define multimedia. For example, the single logical media with words printed on paper is called single media. It is called dual media, such as silent movie, which carries two coding means of image and text. Multimedia, which carries three or more kinds of coding systems at the same time, is called multimedia, such as teaching video, which integrates text, sound and image. Multimodality focuses on the perceptual channel of human senses to the external things or the symbol system of information representation. When the channel of people getting information is single or the information is a single symbol system, it is a single-modal system. Two or more sensing channels are called bimodal or multimodal. For example, the silent movie can be regarded as dual-modality, and the teaching video which integrates text, sound and image is multimodality.

These aspects are consistent with the classification of multimedia. But there are some differences between them, such as paper media, single media with pure text, text image multimedia with illustrations, photos, tables, etc. The first mock exam is that all the paper media, whether single media or multimedia, use visual sense to get information, which is a single modality. For another example, the current micro lesson video, from the perspective of logic coding means, includes three coding systems of text, sound and image, which are three media. From the perspective of multimodality, if the text and video image of the video act on vision and hearing respectively, and audio-visual perception participates in it at the same time, it is bimodal. If the video is only shot by a camera, no matter how many cameras are involved, people can only get a symbol system of information representation, then the video is single modality. If there are multiple input channels such as microphone, camera, computer keyboard, etc., such as video recorded by screen recording software, it is multimodal.

\section{B. Multimodal Theory}

Due to its loose and multi-domain research, multimodal theory has not formed a perfect theoretical system with clear purpose. Multimodal research focuses on social semiotics, systemic functional grammar and discourse analysis. The multimodal theory referred to in this paper is the research viewpoint and results in these fields. The core of multimodal theory is multimodal discourse analysis theory, which was first proposed by Chris and van Leeuwen Out (2001). The main points of multimodal discourse analysis theory include: other symbol systems outside language are also the source of meaning, and can also express meaning. Different modalities have the same symbol principle, which can express the same meaning. Being a social symbol, language has the conceptual function, interpersonal function and textual function, which can be extended to other symbolic systems. Context factors are closely related to the meaning construction of multimodal discourse.

The multimodal learning model constructed by Gu Yueguo (2007) of China Foreign Language Education Research Center is representative in multimodal research. He uses three basic roles to build learning behavior model framework: information acquisition, meaning construction, practical ability, each role includes several sub roles. The role of information acquisition mainly refers to the interaction of human body with the external environment, and its sub roles include: vision, hearing, touch, smell, taste, perception of spatial distance and body imitation. Meaning construction role simulates human brain's processing of external information. Its sub roles include visual information processing, auditory information processing, tactile information processing, olfactory information processing, taste information processing, distance information processing, action information processing and personal knowledge storage. Practical ability is the external behavior performance of learning effect, and its sub roles include traditional listening, speaking, reading, writing and translation skills, as well as body language in face-to-face communication and interaction, namely listening 
ability, speaking ability, reading ability, writing ability, translation ability, body ability, body skill and personal knowledge updating.

On the basis of intensive research, Gu Yueguo proposed five hypotheses about multimodal learning: (1) the same mode learning process is easier than the mode conversion learning process; (2) Appropriate mode switching can enhance learners' internalization of what they have learned and improve the persistence of content memory; (3) Multimodal learning can enhance memory more than unimodal learning; (4) Learning words and images together is better than learning words alone; (5) As to the two ways of learning: face to face with teachers and classmates, and a person alone with computer science, the former is more conducive to enhancing memory than the latter.

\section{Multimodal Teaching}

The development of information technology promotes the improvement of school teaching conditions, the multimodality of meaning representation and information exchange urges us to change the traditional teaching methods and implement multimodal teaching, so as to promote the optimization of classroom teaching. Under the guidance of multimodal theory, multimodal teaching is to coordinate the multimodal system of language, image, sound, action and other meaning construction to become the most effective way of meaning expression and communication, and guide students to construct meaning with the help of multimodal means.

In multimodal teaching, teachers are not only the imparter of knowledge and the player of PPT, but also the selector, cooperator and demonstrator of multimodality. Teachers use multimodal system to design classroom teaching, build multimodal curriculum resources with the help of network learning platform, fully mobilize students' sensory potential, and provide multimodal interactive learning environment for learners to promote learners' multimodal understanding of learning content and multimodal meaning construction.

At the beginning of the 21st century, Stein (2000) introduced multimodal thinking into teaching and put forward multimodal teaching method, emphasizing that curriculum, teaching and evaluation should focus on the modal characteristics of learning environment, and all communication activities in the classroom are multimodal. Multimodal teaching is more used in English teaching. Royce uses images and speech to complement each other in multimodal texts to achieve cross symbol coherence, and uses visual modal stimulation and the presentation relationship between different modes to strengthen English reading, writing, listening, speaking and vocabulary training. Based on practice, he puts forward "multimodal teaching methodology" (Royce, 2002).

Zhang Delu of Ocean University of China studies the effective mode under the condition of modern technology. He points out that mode selection can be carried out from three aspects: (1) It provides teaching situation and convenient conditions for teaching. (2) It provides auxiliary conditions for teaching. (3) It provides multi-channel expression of discourse meaning for multimodal discourse communication (Zhang Delu, 2009).

Shi Junhua of Yantai University discusses and practices the cultivation of multimodal reading ability and multimodal communication ability from the perspective of college English teaching. He believes that today's English reading and writing teaching should be expanded to focus on "multiple discourses" and develop in the direction of multiple reading. Reading and writing ability should not be limited to the understanding and use of language symbols, but should be combined with other symbol systems (Shi Junhua, 2012). With the help of multimedia and other technical tools to construct meaning, one of the significance of English "reading and writing" teaching is to cultivate students' communicative competence. Communication can be carried out through auditory, visual and tactile modes at the same time. Voice, action, gesture, image, color and other communication channels and symbolic modes participate in the process of communication and meaning construction, which is conducive to the cultivation of multimodal communicative competence. O'Halloran of Curtin University in Australia is committed to the research of multimodal discourse analysis theory. He has developed multimodal image and multimodal video software, and actively applied multimodal teaching to middle school mathematics teaching, focusing on the multimodal interaction in mathematics classroom (O’Halloran, 1999).

\section{The Feasibility of ApPlying Multimodal Teaching to FlipPed Classroom}

Compared with the traditional classroom, flipped classroom is a new teaching method, which reverses the two processes of knowledge teaching and knowledge internalization. More importantly, it reverses the status of "teaching" and "learning", and puts "students' learning" in the core position. Multimodal teaching provides a variety of channels for students to obtain, perceive and transfer information. With the help of multimedia and network technology, it can provide more possibilities for students to learn.

\section{A. Flipped Classroom Needs Effective Teaching Mode to Guide}

Flipped classroom is not only the flipping of teaching links, but also the "flipping" of teaching design and teaching implementation under the guidance of new teaching concepts. The premise of this design is that students already have the ability of autonomous learning, and the learning support provided for students is enough to maintain their learning. At present, it's still doubtful whether students have the ability of autonomous learning. Teachers and parents are more worried about whether students will get lost on the Internet and whether they can complete the task of autonomous 
learning with quality and quantity. At any time, we can not replace or force students to learn, and flipped classroom learning is no exception.

However, if we can fully consider students' differences and personalize learning needs in teaching design, mobilize students' participation in various senses with the support of information technology, and implement multi-channel and multi-modal learning, we can always make learners find the most suitable one for their own learning, so as to attract and maintain learners' interest in learning.

Under the traditional teaching conditions, it is almost impossible to achieve. With today's information technology platform, the era of menu learning has come, and the realization of this need is no longer unattainable. In contrast, the current flipped classroom teaching is far from enough in learning support. The quality of many teaching videos is not flattering, and most of them are based on PPT display, with single sensory stimulation and lack of novelty and creativity; Learning materials are limited, and most of them are text and PPT; the communication platform is in vain, and the communication channel is single. The reason for the current situation is that the flipped classroom teaching mode only focuses on teaching content and teaching strategies, and ignores knowledge representation, knowledge presentation and knowledge acquisition methods, which are exactly what students need for autonomous learning.

Constructivism holds that the acquisition and internalization of knowledge is the process of meaning construction by learners through interpersonal cooperation in a certain situation. Internalization of knowledge in class is the core of flipped classroom. The purpose is to leave enough space and time for classroom teaching, so that learners can form a deep understanding of knowledge through exploration and communication. We have reached a general consensus on this point, the existing flipped classroom teaching models mostly pay attention to the importance of creating situations and cooperative activities. However, the current model lacks a deep understanding of the teaching environment, fails to fully reveal the interaction between the individual and the environment, media and artifacts, and is limited to the understanding of the meso dimension of students' activities, which leads to the simple design and implementation of teaching activities.

Therefore, we should not only pay attention to the design of learning resources and media tools, but also pay attention to the design of learning activities and interaction. Technology is not only a medium for spreading knowledge, but also an integral part of distributed cognitive system. It is a tool to support learners' cognitive and learning activities. It can be seen that not all activities can promote students' cognition, we need to realize the essence of activities, promote the deep interaction between learners and external things, build a variety of connection channels between learners and external things, explore the potential of various media resources, and fully display the potential of other people's, time, space, media, then it is possible to support and enrich learners' cognitive activities.

\section{B. Multimodal Teaching Provides a Wide Space for the Implementation of Flipped Classroom}

Multimodal teaching can provide students with multi-modal curriculum resources including video, text, pictures, audio and so on through multimodal means. It can not only meet the needs of learners with different learning orientations, but also enhance the internalization of knowledge through appropriate modal transformation. It can also build multi-modal compound resources for students to learn, Practice has proved that multimodal learning can enhance learners' memory more than single-mode learning. Multimodal teaching can provide students with multimodal network communication platform and multimodal learning tools, mobilize various resources and systems, and build a multimodal learning ring for students' learning.

This not only benefits the cultivation of students' multimodal communication ability, but also cultivates students' practical ability and innovative spirit through different forms of multimodal interaction. Previous studies have shown that face-to-face discussion and communication between people can obtain information from multiple modal channels, which is better than learning from computers alone. It can be seen that multimodal teaching, with the help of the complementary advantages of various modes, participates in the overall construction of meaning, promotes the internalization and understanding of students' knowledge, highlights the characteristics and advantages of flipped classroom, and is conducive to the optimization of teaching.

\section{Construction of Multimodal Teaching Mode}

On the basis of multimodal theory, we can combine with the reference and sublation of previous research results of flipped classroom teaching mode, then construct a new teaching mode, namely multimodal teaching mode, which aims to highlight the characteristics of flipped classroom and give full play to the function of flipped classroom.

\section{A. Design of Multimodal Teaching Mode}

The design of this mode mainly includes two dimensions: teaching structure and multimodal means.

1. The design of teaching structure is based on the characteristics of flipped classroom and the previous research experience. The teaching structure is still divided into two teaching implementation links: in class and after class. According to the different characteristics of students' learning in class and after class, multimodal curriculum, tools and environment are applied to support the teaching structure. 
(1) After class. Through autonomous learning, students can realize the perception and initial internalization of new knowledge. At this stage, multimodal teaching mainly supports learners' autonomous learning through multimodal curriculum resources and multimodal communication platform.

(2) In class. Students' autonomous learning after class can only complete a simple cognition of new knowledge. For more complex multimodal problems, that is, problems involving a wide range and poor structure, students' independent learning alone can not be completed. It needs to be completed through consultation and discussion with teachers and students in class, Group discussion and communication in class is the real essence of flipped classroom. The reason why flipping is implemented is to put the most important content and learning difficulties in the classroom and let everyone study together to complete them, and cultivate students' practical ability, innovative consciousness and innovative spirit in the process of completing the learning task. In class, multimodal teaching is more useful. By providing multimodal curriculum resources, multimodal interaction, multimodal communication platform and multimodal evaluation, multimodal learning environment are built for students to promote the optimization of classroom teaching.

2. Multimodal means design. The design of multimodal means is the focus of multimodal teaching mode design. Taking into account the theory of symbolic system and the theory of interaction mode, we design multimodal means from these two dimensions, that is, the multimodality of symbolic system and the multimodality of communicative mode. The multimodality of symbol system shows the multimodality of meaning expression, such as multimodal curriculum resources. The multimodality of communication mode reflects the diversity of information exchange, such as multimodal interaction mode, multimodal interaction strategy, multimodal learning environment and multimodal evaluation. We need to give full play to the advantages of each mode and tap the potential of each mode to make it complement each other, besides, it's also important to avoid the limitations of single mode.

(1) Multimodal curriculum resources. Whether it is after class or in class, multimodal curriculum resources are the main source of information for students. Different symbolic systems have different ways of expression and advantages, such as text, image (chart), video (animation, micro lesson) and audio (sound), which can meet the learning needs of learners with different aptitudes. Multimodal stimulation is conducive to learners' attention and memory of learning content, so we should design and construct various modal curriculum resources as much as possible. Moreover, with the development of information technology, advanced technology provides the possibility for the integration of multiple modes. As far as possible, audio, text, image and video can be integrated, so that the combination of multiple modes can achieve multi sensory stimulation for learners, and better teaching effect can be achieved. For example, teaching video is one of the main resources for students to learn after class. When making a video, we try to input all the information of voice, PPT and some pictures of the activity when explaining. It's better to input the blackboard with the writing board. At the same time, the writing board input highlights the key points and difficulties of teaching, and it is easy to focus the attention of learners. All these are conducive for students to obtaining as much information as possible from more channels.

(2) Multimodal interaction. Multimodal interaction includes modes and strategies of multimodal interaction. The former mainly includes teacher-student interaction, student-student interaction, group interaction, human-computer interaction, etc. The latter mainly includes role transformation, role play, virtual reality, classroom report, group negotiation and so on. Through a variety of multimodal interaction methods and multimodal interaction strategies, we can mobilize students' multiple senses to participate in cooperation, help students obtain more knowledge understanding from the distributed cognitive environment, promote knowledge internalization, and effectively improve students' practical ability and social communication ability.

(3) Multimodal learning environment. Multimodal learning environment mainly includes technological, cultural and natural dimensions. Technological environment, such as online learning platform (MOOC, Netease open class, Wiki, blogs, Weebly, Sakai, etc.), network communication software (QQ, wechat, Skype, email, Gmail, etc.), search engine (Baidu, Google, CNKI, etc.); cultural environment, such as harmonious and equal interpersonal relationship, active exploration spirit, responsible master attitude, etc; natural environment, such as learning places that meet the needs, natural learning conditions that meet the requirements, etc. The creation of multimodal learning environment can not only help students improve their ability of multiple interaction and the ability of various organs to work together, so that learners can learn happily and easily, but also enable teachers and students to cooperate with each other, promote each other, form a learning community, and stimulate greater potential.

(4) Multimodal evaluation. Multimodal evaluation is to evaluate students' learning results or performance by using multimodal methods. Multimodality can be a process or product. Therefore, we can divide multimodal evaluation into formative evaluation and summative evaluation. Formative assessment mainly focuses on classroom teaching report, role play, learning performance, participation, learning attitude and other process contents in evaluation; summative evaluation is mainly a one-time evaluation of learning results (products), such as paper test, final works, papers, completed projects and so on. The so-called multimodal method is mainly reflected in the multimodal evaluation methods (such as individual evaluation, group evaluation, teacher evaluation, multiple evaluation, etc.), the multimodal evaluation methods (paper evaluation, work exhibition, classroom report, learning performance, report performance, etc.) and the multimodal evaluation dimensions (such as thought, feeling, behavior, cognition, communication, imagination, results, etc.). Multimodal evaluation is consistent with multivariate evaluation, but different from multivariate evaluation, multimodal evaluation not only emphasizes the diversity of evaluation, but also emphasizes 
different information feedback channels. Multimodal evaluation means multi method, multi-channel and all-round evaluation.

\section{B. The Construction Process of Multimodal Teaching Mode}

The design of this mode mainly includes two dimensions: teaching structure and multimodal means.

Based on the above teaching structure design ideas, we divide multimodal teaching into two main links or processes: after class and in class. In class and after class, multimodal problems connect with each other. After class, students mainly study independently, including understanding learning tasks, watching videos, searching materials, communicating and discussing, complete the exercises and pre-class evaluation and other activities. The learning goal is to recognize new knowledge, master factual knowledge, and form the ability of autonomous learning. Through pre-class evaluation, students can get timely feedback, understand their learning effect, and establish multimodal problems encountered in learning, so as to provide problem sources for collective negotiation in class. Class is for multimodal problems, we discuss and negotiate collectively, mainly including problem exchange, independent exploration, group cooperation, achievement display, self-evaluation and group evaluation, summary and reflection and other activities. This process mainly focuses on the complex and ill structured multimodal problems that students encounter in autonomous learning. Under the guidance of teachers, with the help of multimodal resources, multimodal interactive platform, multimodal learning methods, students can solve the problems and form their ability.

In addition to the core flipped classroom teaching structure, this model highlights the construction and role of multimodal learning environment supporting flipped classroom teaching. We believe that in order to better promote learning, we need a variety of multimodal learning environment support, whether it's after class or in class. The creation of multimodal learning environment is the core of multimodal teaching, and also the key to the success of teaching. In the model, open multimodal learning is the environment designed as an encircling structure, encircling the whole teaching structure, which means that the multimodal learning environment should provide 360 degree all-round support for multimodal teaching.

According to the theory of distributed cognition, cognition is distributed within individuals, time, space, environment and society. The cognition of subject is the interaction between cognitive subject and cognitive environment as well as all things related to cognitive activities. It emphasizes that cognitive subject understands cognitive phenomena through interactive activities. A 360 degree multimodal learning environment is conducive to learners' cognition and internalization of knowledge. In flipped classroom, the most beneficial change to students' learning is not after class learning, but the multiple interaction in class. The multimodal interactive activities are the core of classroom activity design. How to design multimodal and interactive activities largely determines the quality of students' knowledge internalization. We should make full use of multimodal teaching resources to promote students to complete the cognition and internalization of new knowledge with the help of multimodal learning platform and interaction mode.

\section{Suggestions on the Implementation of Multimodal Teaching Mode}

When using this teaching mode, we put forward the following suggestions for teachers.

\section{A. Designing the Whole Process of Flipped Classroom with Multimodal Thinking}

The design of this mode mainly includes two dimensions: teaching structure and multimodal means.

Multimodal thinking fits well with the characteristics of flipped classroom. In the teaching design of flipped classroom, multimodal thinking should be fully used to reflect the characteristics of multimodal teaching mode, so as to promote the improvement of flipped classroom teaching quality. First of all, the whole flipped classroom teaching process should be designed with multimodal thinking. Both the design of autonomous learning after class and the design of communication activities in class should embody multimodal thinking. Secondly, the multimodal idea should be implemented in the specific links of teaching implementation. In the design of teaching resources, teaching methods, teaching strategies and teaching evaluation, the multimodal idea and multimodal method should be fully used to tap the potential of resources and environment, meet the needs of students with different sexual orientation as far as possible, and promote the development of each student.

\section{B. Multimodal Interaction in Class Is the Key to Instructional Design}

What flipped classroom focuses on is the two basic teaching processes of students' knowledge imparting and knowledge internalization, rather than simple form flipping. Some teachers spend a lot of energy on the design and preparation of students' learning materials, especially on the design and production of exquisite micro class, ignoring the design and implementation of classroom interaction and communication, which is undoubtedly picking up the sesame and losing the watermelon. The original intention of flipped classroom is to transfer the relatively easy process of knowledge to after class learning, so as to release valuable classroom time to promote students' knowledge internalization. Classroom knowledge internalization is the focus of flipped classroom, teachers need to evaluate the students' learning situation after class on the basis of class communication activities for fine design, so that students can complete knowledge internalization in high-quality interaction. In the design of activities in class, we should not only use the information resources such as multimedia and network, but also make good use of the opportunities of face-to- 
face communication and collective face-to-face negotiation, explore, develop and use various information channels, give full play to the advantages of various modes, and boost learners' understanding and internalization of knowledge.

\section{Creating an Appropriate Multimodal Learning Environment}

Appropriate learning environment is the premise to ensure the smooth progress of learning. A suitable learning environment should at least have the following functions: help arouse students' past experience and understanding, provide rich means of interaction and collaboration, provide rich learning context support, seamlessly integrate rich curriculum resources, and provide instant feedback methods and means. With the help of multimodal resources such as text, image and video, teachers can arouse students' past experience and understanding of new knowledge. Through multi-modal interaction, such as teacher-student interaction, student-student interaction, human-computer interaction, as well as role transformation, role play, virtual reality and other strategies, rich means of interaction and cooperation are provided for students. Teachers can provide timely feedback and guidance for students through multiple and multichannel evaluation mechanism (Ye Xindong, 2014).

However, when creating a multimodal learning environment, the more the better, the more multimodal is relative. Whether it is the multimodal design of symbol system or interactive mode, teachers should provide abundant resources and means as far as possible according to the teaching content, students' characteristics and teaching conditions. Besides, as teachers, we should take the principle of appropriateness, and should not blindly go into the misunderstanding of aiming too high. Secondly, because flipped classroom is a teaching form based on digital media technology, it is easy for people to focus on media technology and ignore the human environment. Compared with media technology, the design and construction of humanistic environment should be the first. We should not fall into the mire of "technology teaching". We should pay attention to the construction of humanistic environment, build equal and harmonious interpersonal relationship, form a positive learning community, and make flipped classroom teaching to achieve twice the result with half the effort.

\section{The Multimodal Evaluation Runs through the Whole Flipped Classroom}

Multimodal evaluation has the functions of diagnosis, stimulation and regulation of teaching. In the whole process of teaching mode design and implementation, we should give full play to the function of multimodal evaluation and make it run through the whole process. According to the principle of "evaluation design prior to teaching design", teachers should first learn from teaching students to achieve the level of learning, design a series of multimodal interactive activities to ensure that each student has excellent performance, so as to collect the development information of students in thought, feeling, behavior, cognition, communication, imagination, results and other aspects, which can help better manage and regulate the flipped classroom. In the pre-class exercise and pre-class evaluation, teachers should have a clear understanding of the knowledge, skills and degree that students should master in the stage of autonomous learning, and design the corresponding measurement methods and indicators.

Through the feedback of students' pre-class practice and pre-class evaluation, teachers can understand the specific situation of students' learning and diagnose the problems in learning, so as to provide content basis for students' communication and discussion in class. In class, teachers should adjust the teaching plan in time according to the feedback of students before class, correct the designed multimodal interactive activities, and carry out the activities in class. Through various modal methods to collect classroom information timely and comprehensively, teachers can provide appropriate help and support for students, guide students to discuss the direction in time, meet the learning needs of students with different aptitudes, adjust the atmosphere, control the rhythm, and ensure the smooth operation of flipped classroom. In addition, multimodal evaluation is not a dissociative event outside of teaching.

Multimodal evaluation itself is a valuable learning resource, which has the significance of teaching value. By making students experience various multimodal evaluation methods, such as self-evaluation, group evaluation, teachers can not only make their learning more effective and self-conscious, then students can naturally learn the methods and skills of evaluation, and form the ability of evaluation. In order to facilitate the comprehensive collection of evaluation information, and to avoid learners' negative emotions about evaluation, especially in the practice and evaluation of preclass learning, teachers should try their best to change the use of text style, chart style, voice style, video style and other modal or multimodal feedback methods, so that students will not take the evaluation as a chore and get bored with the test. In the evaluation, we should adhere to the multimodality of evaluation methods, evaluation dimensions, and give full play to the evaluation function.

\section{REFERENCES}

[1] Dong Liming \& Jiao Baocong. (2014). Research on teaching application model based on flipped classroom. E-Education Research, (7), 108-120.

[2] Forceville, C. \& E. Urios-Aparisi (eds.). (2009). Non-Verbal and Multimodal Metaphor in a Cognitivist Framework: Agendas for Research. New York: Mouton de Gruyter.

[3] Gerstein, J. (2011). The Flipped Classroom Model: A Full Pic-Ture. http: //usergeneratededucation. wordpress.com/2011/06/13/the-flipped-classroom-model-a-ull-picture, (accessed 12/1/2021).

[4] Gu Yueguo. (2007). Analysis of multimedia and multimodal learning. Technology Enhanced Foreign Language Education, (4), 3-12. 
[5] Kress, G. \& Van Leeuwen. (2001). Multimodia Discourse: The Mode and Media of Contempotary Communication. London: Arnold.

[6] Liang Xiaohui. (2015). Cognitive multimodal training mode of English writing thinking. Technology Enhanced Foreign Language Education, (1), 43-49.

[7] O’Hallora, K. L. Towards a systemic functional analysis of multisemiotic mathematies texts. Semiotica, (1): 1-29.

[8] Robert Talbert. (2015). Inverting the Linear Algebra Classroom. https: //prezi.com/dz0rbkpy6tam/inverting-the-linear-algebraclassroom/, (accessed 21/3/2021).

[9] Royce, T. (2002). Multimodality in the TESOL classroom: Exploring visual-verbal synergy. TESOL Quarterly, (2), $191-206$.

[10] Shi Junhua. (2012). Framework design of multimodal college English teaching mode. Education and Vocation, (14), $100-101$.

[11] Stein, P. (2000). Rethinking resources: Multimodal pedagogies in the ESL classroom. TESOL Quarterly, (2), 333-336.

[12] Ye Xindong. (2014). Research on Visual Teaching in Future Classroom Environment. Shanghai: East China Normal University.

[13] Zhang Delu. (2009). The application of multimodal discourse theory and media technology in foreign language teaching. Foreign Language Education, (4), 15-20.

[14] Zhang Jinlei, Wangying \& Zhang Baohui. (2012). Research on flipped classroom teaching mode. Journal of Distance Education. (4), 46-51.

[15] Zhong Xiaoliu, Song Shuqiang \& Jiao Lizhen. (2013). Research on teaching design based on flipped classroom concept in information environment. Education Research, (1), 58-63.

[16] Zhu Yongsheng. (2007). Theoretical basis and research methods of multimodal discourse analysis. Foreign Language Research, (5), 82-86.

[17] Zhu Zhiting \& Guan Qiyu. (2014). Technical force in educational reform. China Educational Technology, (1), 1-9.

Yingjie Liu, female, received her master's degree in English language and literature from Zhongshan University, China in 2005. She is currently an associate professor in the School of Foreign Languages, University of Jinan, China. Her research interests include applied linguistics and ESL teaching. 